\title{
Erratum: "Photoluminescence and electron paramagnetic resonance studies of springlike carbon nanofibers" [Appl. Phys. Lett. 95, 073115 (2009)]
}

Bipin Kumar Gupta, ${ }^{\text {a) }}$ V. Shanker, Manju Arora, and D. Haranath

National Physics Laboratory (CSIR), Dr. K. S. Krishnan Road, New Delhi 110 012, India

(Received 9 September 2009; accepted 10 September 2009; published online 6 October 2009)

[doi:10.1063/1.3241078]

Typographical errors were found in the abstract (line 8, page 073115-1) and summary (line 9, page 073115-3) of our published paper that are related to spin contribution. A "-" was added to superscript of spin contribution value. The sentence should be read as "3.4956 $\times 10^{16}$ spins/g" and also in line 13 from top, right column of page $073115-3$, the value 3.459 $\times 10^{16}$ spins/g must be read as " $3.4956 \times 10^{16}$ spins/g."

a)Electronic addresses: bipinbhu@yahoo.com and guptabgupta@mail.nplindia.ernet.in. 